\title{
Editorials
}

\section{Leadership and responsibility in Public Health Nutrition: time to get serious}

This issue of Public Health Nutrition timed and edited to coincide with the First World Congress in Public Health Nutrition. Congratulations to Professor Lluís Serra Majem and his colleagues for taking the initiative and organising this meeting. The breadth of content and the range of participants are testimony to the relevance and importance of having such a meeting.

As my time as Editor-in-Chief draws to a close, I reflect on where Public Health Nutrition is at the moment, and what we need to focus on in the future. In our first issue in 1998 we stated that one of our aims was to provide an international forum that facilitates a dialogue between theory, research and practice ${ }^{1}$.

\section{Progress to date}

While we have published papers on theory and research, and increasingly findings from intervention and evaluation studies, we have not yet succeeded in also becoming a forum for discussion and dissemination of best practice. If we are really going to make a difference to the well-being of those who are worst off in the world, and in our own countries, we have to develop closer links between teaching, research and service or practice-based activities.

Other mature professions have a clearer sense of their professional responsibilities than I feel we have in Public Health Nutrition. We need to build stronger links and support structures and systems between all sectors involved in Public Health Nutrition, and I hope that the journal will expand its role in strengthening these links. I believe we need to ask more relevant questions as to what we (not others) need to do really to make a difference, to exercise and take responsibility for Public Health Nutrition. And we must support and strengthen our own professional competence and capacity if we are to be taken seriously by the wider community. While it is essential that we reach out to other professional groups, we must make sure our own house is in order - that we have the appropriate knowledge and skills, tools and professional code of conduct to guide our approach.

The journal has published papers that have explored the skills and knowledge required to be a public health nutritionist. Jackie Landman, Roger Hughes and Agneta Yngve have led the development which has articulated what it means to be competent and fit to practice in Public Health Nutrition $^{2-4}$. This work - alongside the ongoing strengthening of the methodological base the profession is built on - will, I hope, to continue to feature in Public Health Nutrition. All professionals need tools to work with, and we must make sure that these tools are the best they can be, that we understand the limitations of our current approaches and stimulate ways to improve them, recognising the practical real-world context in which we need to be able to translate evidence into action.

\section{Getting our own house in order}

We also need to ensure that the way in which the journal runs, and the way the journal relates to the wider world, is open and transparent, and that we define and follow ethical principles of best practice. In a recent editorial I commented on a number of issues related to fraud and the way industry uses scientists ${ }^{5}$. This has led us to ensure that the journal is a part of the wider publishing community that agrees to and follows a code of best practice ${ }^{6,7}$. The journal is in the process of establishing a policy on dealing with conflicts of interest for authors, reviewers and editors. It is not our role to be the moral judge and jury and I do not believe in censorship, but I do believe readers should know who funds our work.

We have also commented on the way people are appointed to senior international posts, and this has also caused us to reflect on the way we do our own business ${ }^{8}$. I am pleased that the way Agneta Yngve has been appointed as the new Editor-in-Chief has been more open and transparent than the way I was appointed. I wish Agneta well in taking over the editorship of the journal.

Related to this we have discussed in the journal the way that industry and other groups fund research; Este Vorster proposed that ideally there should be a blind trust into which money was placed and then drawn out, without being able to link the funder with the recipient ${ }^{9}$. While this may appear naïve and unworkable, it still seems like the only way to control potential manipulation by vested interests.

\section{Future challenges}

We cannot get away from the reality that global food supplies are increasingly controlled by fewer and fewer powerful groups, and that increasingly the populations of the world rely on buying food, rather than growing and preparing it for themselves. 
This trend has two important consequences that Public Health Nutrition must engage in more vigorously. First, the ecological and environmental consequences of the way food is grown and distributed; and second, the impact of the way foods are prepared on their fat, salt and sugar content. I believe we have a major role not only to inform people about what is happening to their food supply, but also to actively engage to improve it. We need to be far less naïve about the working of industry, and work with policy-makers to ensure they are brave and make the right decision in terms of improving access to good-quality food for the worst off in society.

This means that we must ensure that policy-makers are well informed and well armed to make judgements as to what is the best course of action - certainly that they need to be more aggressive and think beyond a narrow role of simply telling people and letting them make judgements about what to do.

Informed choice is fine for those who can exercise it, but the majority of the people of the world have little control, and we must not be so naïve as to think the solution to all food-related problems is technical and can be solved by companies identifying a perfect new food cocktail that meets all nutritional needs.

We need to ask why people eat the way they do, define the key constraints in the widest sense possible, and act to address these constraints. Functional foods and technically expensive new foods will never make any real difference to the diets of the poorest. We also need to engage in this in a way that is not patronising to the groups we are trying to 'help'. From my experience most people know what to do for the good of their families, they just aren't allowed or able to do it.

\section{Getting serious}

By being Editor-in-Chief of this journal I have had the privilege of being forced to think about what the purpose of a journal is, and indeed the purpose of our professional lives. We must observe, report and educate ourselves and others, but most of all we must engage in translating evidence into action, building and strengthening the structures and systems in society that deliver and ensure health for all. This means taking our responsibilities seriously, this means behaving professionally, this means acting collectively for the greater good, this means standing up and being counted.

If we want to be taken seriously, we have to take the responsibility that comes with power - to act collectively for what is in the best interest of the society we serve. We have to recognise that what makes Public Health Nutrition relevant is that it engages in and solves problems; in other words, it is the 'service' role that is critical. This means that it has to be soundly rooted in academic excellence, be guided by clear philosophy and principles, to ensure that at all times we behave professionally. We must be judged by our actions, not by our words alone.

Public Health Nutrition will be the forum for communication and debate about the nature of what needs to be done and the best way to do it - which means the journal must have a role that is wider than simply receiving and accepting or rejecting original contributions. The journal must engage actively in discussion about the big issues that affect the nutrition-related well-being of society. The journal must be an example of best practice in terms of defining, adopting and following standards of best practice. Although rooted in biological science, the journal must continue to recognise that nutrition is also deeply rooted in all aspects of society, and indeed the whole physical and living world, and therefore if we are to engage in finding ways to make a difference we have to accept, work with and understand this wider social, environmental and cultural context. We must also face the political realities of the world we live in, and accept that to change policy we have to get involved, understand, and influence decision-makers and decision-making processes.

Barrie Margetts

Editor-in-Chief

DOI: 10.1079/PHN2006978

\section{References}

1 Margetts B, Kohlmeier L, Nelson M, Kok F. Editorial. Public Health Nutrition 1998; 1: 1-3.

2 Hughes R. Competency development needs of the Australian public health nutrition workforce. Public Health Nutrition 2003; 6: 839-47.

3 Yngve A, Warm D, Landman J, Sjostrom M. European Master's Programme in Public Health Nutrition. Public Health Nutrition 2001; 4: 1389-91.

4 Yngve A, Sjostrom M, Warm D, Margetts B, Perez Rodrigo C, Nissinen A. Effective promotion of healthy nutrition and physical activity in Europe requires skilled and competent people; European Master's Programme in Public Health Nutrition. Public Health Nutrition 1999; 2: 449-52.

5 Margetts BM. Stopping the rot in nutrition science [editorial]. Public Health Nutrition 2006; 9: 169-73.

6 Anon. Summary of cases submitted. In: COPE Annual Report 2001. Committee on Publications Ethics. London: BMJ Publishing Group, 2002; 26. Also available at http://www. publicationethics.org.uk/reports/2001.

7 COPE (Committee on Publication Ethics) homepage: http:// www.publicationethics.org.uk.

8 Margetts B. Editorial. Public Health Nutrition 2005; 8: 21920.

9 Vorster H. Sponsorship of nutrition research in developing countries. Public Health Nutrition 2001; 4: 1015-22. 